\title{
Design of Optimal Temperature Distribution using FEA for Warm Forming of Lightweight Materials
}

\author{
Hong Seok Kim, Muammer Koç*, Jun Ni \\ S. M. Wu Manufacturing Research Center, College of Engineering, University of Michigan, MI, USA
}

\begin{abstract}
This paper presents a methodology to determine proper temperature levels and zones for successful warm forming of lightweight materials. A comparison of experimental and finite element analysis (FEA) results is presented to verify the effectiveness of FEA in warm deep drawing and rectangular pan forming processes. A new methodology to determine the proper temperature distribution of tooling and blank was proposed using design of experiments (DOE) and FEA. Results of this method were compared with those of alternative approaches. The proposed method offers alternatives for rapid and relatively accurate predictions and design of warm forming process especially for large parts that require 3D FEA.
\end{abstract}

\section{INTRODUCTION}

Lightweight materials such as $\mathrm{Al}$ and $\mathrm{Mg}$ alloys have been increasingly demanded in the automotive industry as substitutes for steel sheet metal to achieve low-mass vehicles to increase fuel efficiency and reduce emission. Even though there is a large potential of using lightweight materials for the body and chassis structures for further fuel savings, the justification for replacement of lightweight materials over steel is very questionable with conventional production processes because of the high material cost and formability limitation [1-9].

In order to achieve increased formability of lightweight materials, warm forming process has been widely investigated since 1970 s as an alternative manufacturing process [1-11]. Shehata et al. [1] carried out the tensile tests of Al-Mg alloys (0-6.6. $\mathrm{Mg} \%)$ at warm temperature conditions $\left(20-300^{\circ} \mathrm{C}\right)$, and a substantial increase in elongation with increasing temperature and decreasing strain-rate has been reported. Li et al. [2] also investigated uniaxial ductility of three aluminum sheets, Al 5754, Al 5182+Mn, and $\mathrm{Al}$ 6111-T3, and showed that the enhancement of strain rate sensitivity with increasing temperature accounts for the ductility improvement at elevated temperature. Warm forming experimental results for deep drawing [3-7] and rectangular pan forming $[8,9]$ of various lightweight materials showed that increasing temperature increases formability. It was also demonstrated that keeping the punch cool would help increase the formability [3-8]

For the successful application and optimal design of warm forming process, it is required to fully understand the complex warm forming characteristics such as mechanical behavior of materials, interface conditions, and factors influencing formability in a wide range of temperatures. However, sophisticated analytical models that account for comprehensive warm forming characteristics have not been fully developed yet, therefore, so far, the design of warm forming process and tooling is highly dependent on either the experimental works [3-9] that consume significant amount of time, manpower, and cost or trial and error based numerical simulations $[10,11]$

Recent progresses in FEA enabled a remarkable development in metal forming and led to shorter lead time and cost saving. Takuta et al. [11] developed a combined numerical model using the rigid-plastic and the heat conduction finite element methods to analyze the deformation behavior of an aluminum alloy sheet (Al 5182-O) at elevated temperature. Through the comparison between the experimental and the predicted results, the effectiveness and reliability of FEA has been verified. Improved formability is attained in warm forming temperature of $250{ }^{\circ} \mathrm{C}$ and the necking sites are successfully predicted by the

\footnotetext{
${ }^{*}$ Corresponding author

E-mail address: mkoc@umich.edu
}

CP712, Materials Processing and Design: Modeling, Simulation and Applications, NUMIFORM 2004, edited by S. Ghosh, J. C. Castro, and J. K. Lee

(C) 2004 American Institute of Physics 0-7354-0188-8/04/\$22.00 
simulation. Palaniswamy et al. [10] demonstrated the feasibility of FEA tools (2D and 3D) in predicting material flow and thickness variation after experimental validation based on experimental study by Doege et al. [12]. Alternatively, many researchers used FEA in combination with different optimization techniques (such as response surface methods, adaptive controlled FEA, neural networks, and genetic algorithm) to reduce the number of simulation and develop re-usable guidelines [13,15-17].

This paper presents (a) application and validation of 2D warm forming FEA of aluminum alloys based on the experimental work by Naka et al. [3], (b) validation of 3D FEA with experimental results by $\mathrm{Li}$ et al. [9], and (c) an alternative method to rapidly, accurately, and cost effectively determine optimal (acceptable) temperature distribution for warm forming based on combined DOE/isothermal FEA and few additional non-isothermal FEA. Application of the DOE in combination with FEA broadens the fundamental understanding of warm forming mechanisms.

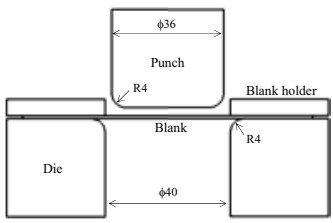

(a) FE model

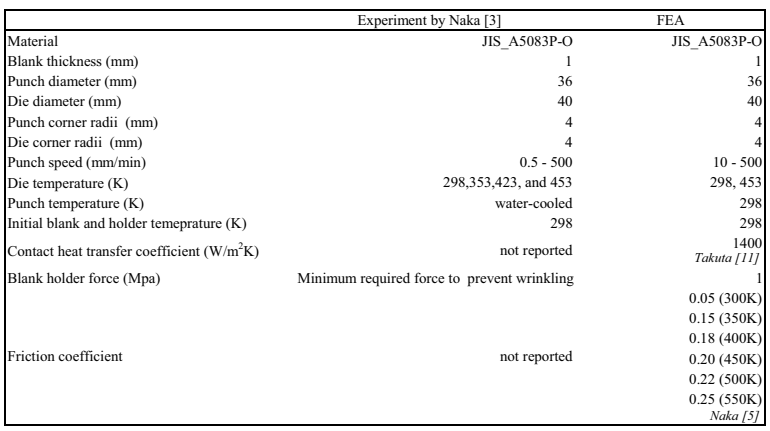

(b) Simulation conditions

FIGURE 1. Deep drawing simulation model.

\section{FEA MODELING AND ANALYSIS FOR WARM FORMING OF ALUMINUM ALLOYS}

In order to verify the effectiveness of FEA in warm forming, FE models for 2D deep drawing and 3D rectangular pan forming are developed. Thermomechanically coupled analysis using a commercial FEA code, ABAQUS, is conducted to reflect non- isothermal warm forming condition. Simulation results are compared with experimental measurements.

\section{D FEA for Deep Drawing}

Naka et al. [3] performed cylindrical deep drawing tests to experimentally investigate the effects of forming speed and temperature on deep drawability. In order to validate the accuracy and efficiency of FEA in warm deep drawing conditions, their experimental conditions are projected into an FE model as shown in Fig. 1.

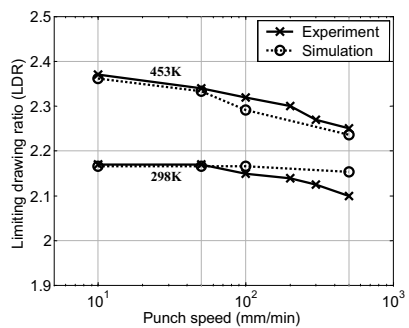

FIGURE 2. Comparison of limiting drawing ratios at various temperature levels and punch speed values.

As shown in Fig. 2, the present authors [14] compared the predicted and measured limiting drawing ratio (LDR) at various temperatures and strain rates. In the lower speed region $(10-100 \mathrm{~mm} / \mathrm{min})$, the predicted LDR values were very close to the experimental measurements as reported by Naka et al. [3]. In the higher speed region, on the other hand, simulation results showed some discrepancy with the experimental results. However, the maximum difference between FEA prediction and experimental measurement was about $2.3 \%$, and the general LDR trend obtained from simulation matched well with that from experiments. Detailed discussions on analysis and comparisons can be found in a previous prepared paper [14].

\section{D FEA For Rectangular Pan Forming}

$\mathrm{Li}$ et at. [9] investigated the warm forming behavior of three aluminum alloys (Al 5754, Al $5182+\mathrm{Mn}$, and $\mathrm{Al} 6111-\mathrm{T} 4)$ by performing rectangular pan forming tests in warm forming conditions. FE simulations of rectangular pan forming were conducted at various tooling temperatures and blank holder pressures for $\mathrm{Al} 5182+\mathrm{Mn}$. In order to simulate non-isothermal warm forming process, a thermomechanically coupled FEA model is developed using ABAQUS/Explicit. For simplicity, tools are assumed to be rigid, and uniform temperature distribution is directly assigned on the tooling surfaces. Blank temperature was initially $25{ }^{\circ} \mathrm{C}$ and allowed to change during the process by the conduction heat transfer 
from the tooling. To consider the heat transfer effect at interface, a 3D brick element, C3D8RT, having both temperature and displacement as its degrees of freedom is used to describe the model.

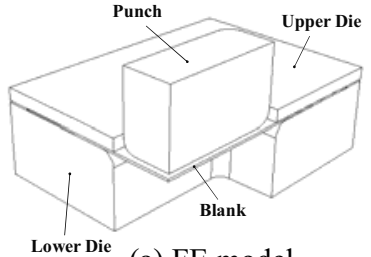

(a) FE model

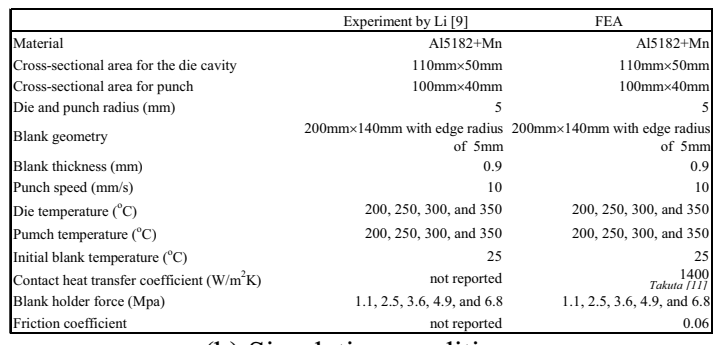

(b) Simulation conditions

FIGURE 3. Rectangular pan forming simulation model.

Figure 3 (a) shows a quarter of the geometry modeled according to the symmetry boundary conditions, and geometrical features and process parameters are tabulated in Fig. 3 (b). Stress-strain relationships of $\mathrm{Al} 5182+\mathrm{Mn}$ measured at three temperatures $\left(25,200\right.$, and $\left.350{ }^{\circ} \mathrm{C}\right)$ and three strain rates $\left(0.015,0.15,1.5 \mathrm{~s}^{-1}\right)$ are obtained from $\mathrm{Li}$ et al. [2], and used to describe the plastic behavior of the blank material. Few parameters that are not reported in the paper are determined based on the information from other papers for the same or similar process condition. The contact heat transfer coefficient is obtained from the study of Takuta et al. [11], and the average friction coefficient is selected based on the measurement of flat-sheet drawing tests conducted by Naka et al. [5]. Both are assumed to be uniform regardless of the temperature and pressure at interface.

Figure 4 shows the comparison of part depths obtained from experiments and FEA simulations at various die-punch temperature combinations. The part was considered to fail when more than $30 \%$ thinning occurred. When the die temperatures were 250 and $300^{\circ} \mathrm{C}$, part depths predicted from the simulations matched with experimental measurements reasonably. The maximum differences were about $34 \%$ when $\mathrm{T}_{\mathrm{die}}=250{ }^{\circ} \mathrm{C}$ (Fig. 4 (b)), and $15 \%$ when $\mathrm{T}_{\mathrm{die}}=300{ }^{\circ} \mathrm{C}$ (Fig. 4 (c)). However, in general, higher part depth values were predicted when the die temperature was $200{ }^{\circ} \mathrm{C}$. In this case, the maximum difference was around $100 \%$ with the same trend. On the other hand, the predicted failure trend was different with the experimental results at the die temperature of $350^{\circ} \mathrm{C}$.
In this case, the maximum difference between FEA prediction and experimental measurements was around $50 \%$ occurring at high temperature gradient (i.e. $\mathrm{T}_{\text {die }}=350, \mathrm{~T}_{\text {punch }}=200{ }^{\circ} \mathrm{C}$ ). The difference reduces down to $5 \%$ at isothermal condition at $350{ }^{\circ} \mathrm{C}$ (i.e. $\mathrm{T}_{\mathrm{die}}=350$, $\mathrm{T}_{\text {punch }}=350{ }^{\circ} \mathrm{C}$ ).

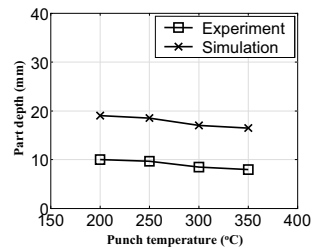

(a) $\mathrm{T}_{\mathrm{die}}=200{ }^{\circ} \mathrm{C}$

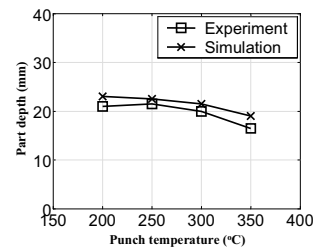

(c) $\mathrm{T}_{\mathrm{die}}=300^{\circ} \mathrm{C}$

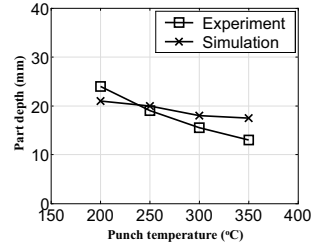

(b) $\mathrm{T}_{\text {die }}=250{ }^{\circ} \mathrm{C}$

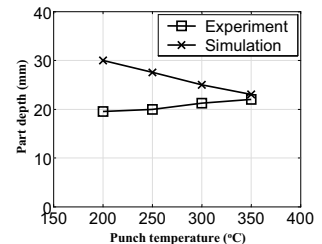

(d) $\mathrm{T}_{\mathrm{die}}=350{ }^{\circ} \mathrm{C}$
FIGURE 4. Effect of die and punch temperature on part depth (blank holder force $=1.1 \mathrm{MPa}$ ).

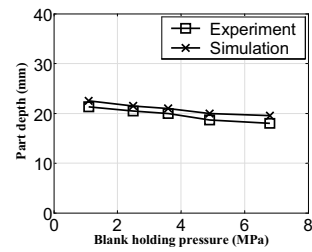

(a) $\mathrm{T}_{\text {die }}-\mathrm{T}_{\text {punch }}=300-250^{\circ} \mathrm{C}$

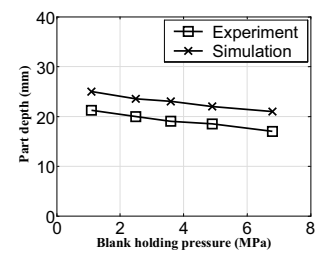

(a) $\mathrm{T}_{\text {die }}-\mathrm{T}_{\text {punch }}=350-300^{\circ} \mathrm{C}$

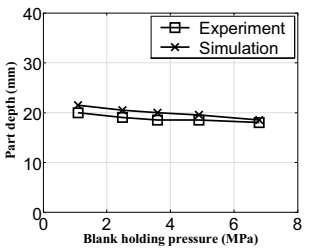

(b) $\mathrm{T}_{\text {die }}-\mathrm{T}_{\text {punch }}=300-300^{\circ} \mathrm{C}$

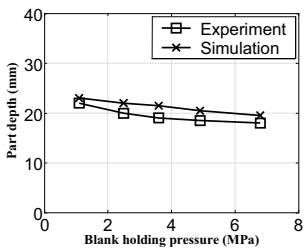

(b) $\mathrm{T}_{\text {die }}-\mathrm{T}_{\text {punch }}=350-350^{\circ} \mathrm{C}$
FIGURE 5. Effect of blank holder pressure on part depth at different die-punch temperatures.

The effect of blank holder pressure (BHP) on part depth is shown in Fig. 5 under different temperature conditions. The trend of depth variation with blank holder pressure matched well with the experimental findings. Lower BHP was preferred for the improved formability. However, higher part depth values were predicted at all temperatures and blank holder pressures with FEA when compared to experiments. The difference between FEA prediction and reported experimental measurements reached a maximum of $23 \%$ at $\mathrm{T}_{\text {die }}=350, \mathrm{~T}_{\text {punch }}=300^{\circ} \mathrm{C}$, and $\mathrm{BHP}=6.8 \mathrm{MPa}$, and a minimum of $5 \%$ at $\mathrm{T}_{\mathrm{die}}=350, \mathrm{~T}_{\text {punch }}=350{ }^{\circ} \mathrm{C}$, and $\mathrm{BHP}=1.1 \mathrm{MPa}$. 
The deviation between FEA prediction and experimental measurements could be due to (a) incomplete material property definitions used in the FEA: The material properties were digitized from Li et al. [9]. During this transformation, there might be some human error. In addition, only flow stress curves at 25,250 , and $350{ }^{\circ} \mathrm{C}$ are reported in Li et al. [9]. The rest was interpolated, hence, there might be some inaccuracy caused by this transformation, too, (b) incorrect and incomplete assumption of process parameters: Constant heat transfer coefficient, friction coefficient and uniform temperature distribution on the tooling were assumed in FEA. However, in reality, all of these parameters vary spatially and temporally, and (c) possible errors in reporting of experimental results. Moreover, it is well known and accepted that characterization of material behavior, friction condition, and heat transfer coefficient at elevated temperature condition are difficult and may result in inaccurate measurements and findings $[3,9]$.

In summary, the overall trend of material behavior at warm forming conditions was successfully predicted under various process conditions in 2D deep drawing and $3 \mathrm{D}$ rectangular pan forming processes. The effectiveness of FEA to analyze complex interactions between material and process parameters are confirmed.

\section{DOE TO DETERMINE APPROPRIATE TEMPERATURE LEVELS AND ZONES}

Having demonstrated the efficiency and reasonably acceptable accuracy of FEA techniques for warm forming process in the previous section, determination and design of appropriate temperature levels and zones on the tooling to achieve high formability will be presented in this section. Mainly three approaches can be taken to determine optimal temperature distribution in warm forming: (a) Effect of temperature distribution of tooling on formability can be analyzed using the combined DOE/non-isothermal FEA: This method would offer accuracy at the expense of costly and lengthy simulations, particularly for 3D large part cases, (b) Regional temperatures of the blank can be considered as design factors without considering the heat transfer with the tooling: In this case, isothermal FEA can be used because the conduction heat transfer at interface can be ignored. The determined temperature distribution on the blank, then, can be mapped onto the tooling regions for few additional non-isothermal FEA for validation. With this approach, we can achieve accurate result at a reduced CPU time usage, and (c) Other optimization techniques such as adaptive control FEA, neural networks, and genetic algorithm can be used to find the optimal heating mode of warm forming process as reported in literature for other process parameters [15-17]. In this paper, the results of the approaches (a) and (b) are presented and compared, Fig. 6.

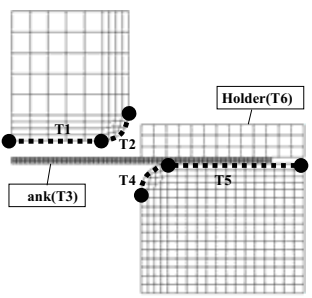

(a) non-isothermal FEA

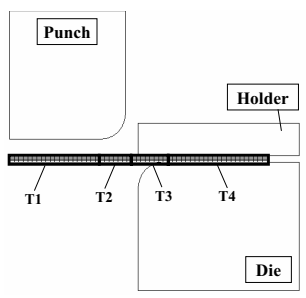

(b) isothermal FEA
FIGURE 6. Illustration of the main difference between nonisothermal and isothermal FEA

\section{Combined DOE/Non-Isothermal FEA Approach}

As shown in Fig. 7, six independent factors (two regional temperatures (T4, T5) for the die, two for the punch (T1, T2), holder temperature (T6), and initial blank temperature (T3)) are selected as design variables, and two temperature levels $\left(25^{\circ} \mathrm{C}, 250^{\circ} \mathrm{C}\right)$ are assigned to each variable.

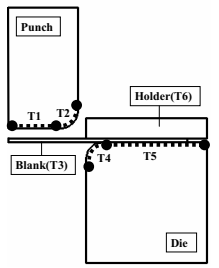

\begin{tabular}{|ccc|}
\hline & level 1 & level 2 \\
\hline $\mathrm{T} 1\left({ }^{\circ} \mathrm{C}\right)$ & 25 & 250 \\
$\mathrm{~T} 2\left({ }^{\circ} \mathrm{C}\right)$ & 25 & 250 \\
$\mathrm{~T} 3\left({ }^{\circ} \mathrm{C}\right)$ & 25 & 250 \\
$\mathrm{~T} 4\left({ }^{\circ} \mathrm{C}\right)$ & 25 & 250 \\
$\mathrm{~T} 5\left({ }^{\circ} \mathrm{C}\right)$ & 25 & 250 \\
$\mathrm{~T} 6\left({ }^{\circ} \mathrm{C}\right)$ & 25 & 250 \\
\hline
\end{tabular}

FIGURE 7. Design variables in the combined DOE/nonisothermal FEA.

TABLE 1. Simulation conditions for the non-isothermal simulation.

\begin{tabular}{|lr|}
\hline Material & JIS_A5083P-O \\
Blank diameter $(\mathrm{mm})$ & 108 \\
Blank thickness $(\mathrm{mm})$ & 1 \\
Punch diameter $(\mathrm{mm})$ & 36 \\
Die diameter $(\mathrm{mm})$ & 40 \\
Punch corner radii $(\mathrm{mm})$ & 4 \\
Die corner radii $(\mathrm{mm})$ & 4 \\
Punch speed $(\mathrm{mm} / \mathrm{s})$ & 2.5 \\
Contact heat transfer coefficient $\left(\mathrm{W} / \mathrm{m}^{2} \mathrm{~K}\right)$ & 1400 \\
Blank holder force $(\mathrm{Mpa})$ & 2 \\
Friction coefficient & 0.1 \\
\hline
\end{tabular}

The model geometry and detailed simulation conditions are presented in Table 1. Plastic properties of 5083-O Al-Mg alloy measured at five different temperatures $(293,353,423,473$, and $523 \mathrm{~K})$ and at a wide range of strain rates $\left(5.56 \times 10^{-5}, 5.56 \times 10^{-4}\right.$, $5.56 \times 10^{-3}, 5.56 \times 10^{-2}, 5.58 \times 10^{-1}$, and $\left.52.9 \times 10^{-1} \mathrm{~s}^{-1}\right)$ 
were taken form Naka [3], and used as the blank material. Geometric features are the same with those of Naka [3], and process parameters other than tooling and blank temperatures are all fixed in order to focus on the temperature effect on deep drawability. A thermally-coupled 4-node bilinear axisymmetric element, CAX4RT is used to describe the entire model.

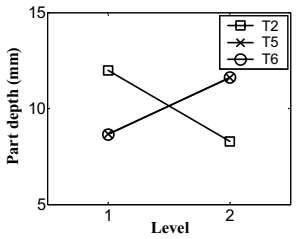

(a) Main effects

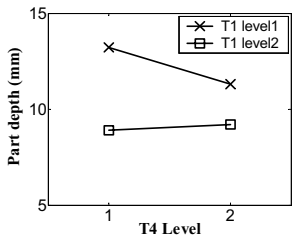

(b) Interaction effect $(\mathrm{T} 1 \times \mathrm{T} 4)$
FIGURE 8. Response graphs for the combined DOE/nonisothermal FEA.

By borrowing one column from the base full factorial design, a number of $2^{6-1}=32$ simulations were performed, and the main effects and two-factor interaction effects are examined. The calculations for determining the effect of a factor (or interaction) are performed by selecting all values of the response (part depth before failure) at each factor level, taking the sum, and dividing by the number of values at each level. The absolute difference between two averages is the effect of the factor. In this study, T2 (punch corner region) has the greatest effect on the achievable part depth, and next are T6 (holder), T5 (die flat region), and interaction $\mathrm{T} 1 \times \mathrm{T} 4$ (punch flat region $\times$ die corner region). The individual and interaction effects of relevant factors are illustrated in Fig. 8. For the improved drawability, level $1\left(25^{\circ} \mathrm{C}\right)$ for $\mathrm{T} 1, \mathrm{~T} 2$, and $\mathrm{T} 4$, and level $2\left(250^{\circ} \mathrm{C}\right)$ for $\mathrm{T} 5$ and $\mathrm{T} 6$ are recommended because higher part depth means greater formability.

TABLE 2. Recommended heating condition for the combined DOE/non-isothermal FEA.

\begin{tabular}{|ccc|}
\hline Importance & Variable & Recommended level \\
\hline 1 & $\mathrm{~T} 2$ (punch corner region) & $25^{\circ} \mathrm{C}$ \\
2 & $\mathrm{~T} 6$ (holder) & $250{ }^{\circ} \mathrm{C}$ \\
3 & $\mathrm{~T} 5$ (die flat region) & $250^{\circ} \mathrm{C}$ \\
& $\mathrm{T} 1 \times \mathrm{T} 4$ (punch flat region $\times$ die corner & $\mathrm{T} 1=25^{\circ} \mathrm{C}$ \\
4 & region) & $\mathrm{T} 4=25^{\circ} \mathrm{C}$ \\
\hline
\end{tabular}

The recommend heating condition is summarized in Table 2. The insignificance of blank temperature appears to be due to the fast heat transfer from the tooling because aluminum alloy used for the blank material has relatively smaller volume and higher conductivity. The confirmation run showed further improvement of the part depth, and confirmed the deduced conclusion. However, it seems to be very difficult to realize the recommended heating condition in the actual tooling model due to the large temperature difference on the same die (T4 is $25^{\circ} \mathrm{C}$ and $\mathrm{T} 5$ is $250^{\circ} \mathrm{C}$ ). Local cooling channels, as used in the experiments of Moon et al [7], can be adopted for the efficient cooling of the punch corner.

\section{Proposed Method: Combined DOE- Isothermal FEA-Non-Isothermal FEA}

The effect of temperature distribution on the blank material was investigated. As shown in Fig. 9, four temperature regions on the blank were selected as independent factors, and three temperature levels (25, $137.5,250{ }^{\circ} \mathrm{C}$ ) are assigned to each factor. Geometric features and simulation conditions are not changed as in the previous DOE. However, simulations are conducted in the isothermal condition meaning that conduction heat transfer between tooling and blank is ignored.

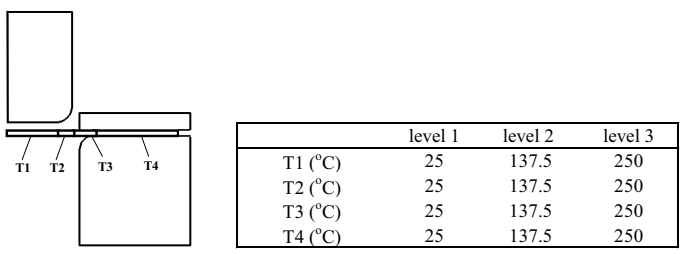

FIGURE 9. Design variables in the combined DOE/isothermal FEA.

As a result of a similar procedure as described in the previous method, T2 (punch corner region) showed the strongest effect and followed by $\mathrm{T} 4$ (die flat region). Next was the interaction $\mathrm{T} 1 \times \mathrm{T} 2$ (punch flat region $\times$ punch corner region). As shown in Fig. 10, the preferred levels for the factors that exhibited a strong effect were level $1\left(25^{\circ} \mathrm{C}\right)$ for $\mathrm{T} 1$ and $\mathrm{T} 2$, and level $3\left(250{ }^{\circ} \mathrm{C}\right)$ for T4. As tabulated in Table 3, the recommended heating condition of the blank matched well with the result of the previous approach that involves non-isothermal FEA. The determined temperature distribution on the blank, then, can be transferred and mapped onto the corresponding tooling elements for few additional non-isothermal FEA to validate and finalize the result.

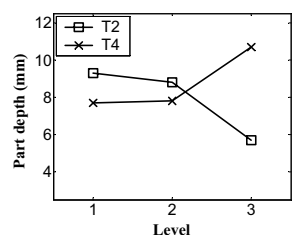

(a) Main effects

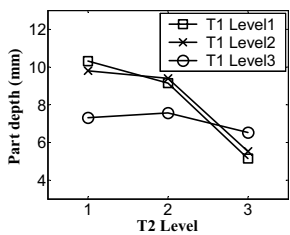

(b) Interaction effect $(\mathrm{T} 1 \times \mathrm{T} 2)$
FIGURE 10. Response graphs for the combined DOE/isothermal FEA.

It is understood that this approach contains some erroneous factors including the movement of assigned 
temperature regions on the blank during forming, and issues with the selection and borders of temperature regions. Since the temperature distribution on the blank is mainly determined by the temperature of the contacting tooling region, blank temperature changes as the process progresses, and it is not a controllable factor in the real forming condition. However, as proved in this study, the relative importance of the temperature region and levels on the blank were accurately predicted by this approach. With the DOE/isothermal FEA, not only will the required number of simulation be reduced, but also necessary CPU time will be reduced since particularly for simulation of large parts, 3D explicit codes with shell elements can be used only for isothermal condition. For non-isothermal cases (thermo-mechanically coupled analysis), solid elements have to be used, and that requires longer CPU times (i.e., in the order of 510 times). In case of $2 \mathrm{D}$ deep drawing process, time savings was not too apparent because of the simplicity and small size of the model. However, in case of the $3 \mathrm{D}$ rectangular pan forming model, the required time for an isothermal simulation was $3 \mathrm{hr}$ while $25 \mathrm{hr}$ was required for a non-isothermal simulation. The applicability of this approach will be further investigated through the simulations of various $2 \mathrm{D}$ and 3D models.

TABLE 3. Recommended heating condition for the combined DOE/isothermal FEA.

\begin{tabular}{|ccc|}
\hline Importance & Variable & Recommended level \\
\hline 1 & $\mathrm{~T} 2$ (punch corner region) & $25^{\circ} \mathrm{C}$ \\
2 & $\mathrm{~T} 4$ (die flat region) & $250^{\circ} \mathrm{C}$ \\
3 & $\mathrm{~T} 1 \times \mathrm{T} 2$ (punch flat region $\times$ punch corner & $\mathrm{T} 1=25^{\circ} \mathrm{C}$ \\
4 & region) & $25^{\circ} \mathrm{C}$ \\
\hline
\end{tabular}

\section{CONCLUSION}

In this study, thermo-mechanically coupled FE models for 2D deep drawing and 3D rectangular pan forming processes were developed. Even though there were deviations in the prediction of part depths and limiting drawing ratios, the general trend matched well with the experimental measurements.

Appropriate heating conditions and possible temperature ranges of the tooling and blank were examined in deep drawing process using both FEA and DOE techniques. Regional heating/cooling effects of the tooling on drawability were investigated. The improved formability is achieved by the heating of the flange region and the cooling of the punch and die corner region. Another DOE analysis considering the regional temperatures of the blank as design variables is performed to reduce the required simulation time. The predicted optimal (acceptable) temperature distribution agreed with the results from the nonisothermal simulations.

In addition to the combined DOE/FEA approach, various optimization techniques such as adaptive control FEA, neural networks, and genetic algorithm will be examined to determine the optimal temperature distribution on a given warm forming system more effectively with much reduced number of FEA runs. Eventually, simulation results will be compared with experiments using an actual inner door panel tooling in collaboration with the Department of Energy USCAR Warm Forming of Aluminum project members.

\section{REFERENCES}

1. Shehata, F., Painter, M. J., and Pearce, R., Journal of Mechanical Working Technology 2, 279-290 (1978).

2. Li, D., and Ghosh, A., Materials Science and Engineering A352, 279-286 (2003).

3. Nake T., and Yoshida, F., Journal of Materials Processing Technology 89-90, 19-23 (1999).

4. Takata, K., Ohwue, T., Saga, M., and Kikuchi, M., Materials Science Forum 331-337, 631-636 (2000).

5. Naka, T., Hino, R., and Yoshida, F., Key Engineering Materials 177-180, 485-490 (2000).

6. Doege, E., and Dröder, K., Journal of Materials Processing Technology 115, 14-19 (2001).

7. Moon, Y. H., Kang, Y. K., Park, J. W., and Gong, S. R., International Journal of Machine Tools and Manufacture 41, 1283-1294 (2001).

8. Bolt, P. J., Lamboo, N.A.P.M., and Roizer, P.J.C.M., Journal of Materials Processing Technology 115, 118121 (2001).

9. Li, D., and Ghosh, A., Journal of Materials Processing Technology 145, 281-293 (2003).

10. Palaniswamy, H., Ngaile, G., and Altan, T., Journal of Materials Processing Technology 146, 108-115 (2004).

11. Takuta, H., Mori, K., Masuda, I., Abe, Y., and Matsuo, M., Journal of Materials Processing Technology 120, 412-418 (2002)

12. Dröder, K. Analysis on Forming of Thin Magnesium Sheet, Ph.D. thesis, IFUM, University of Hanover (1999).

13. Koç, M., Allen, T., Jiratheranat, S., and Altan, T., International Journal of Machine Tools and Manufacture 40, 2249-2266 (2000).

14. Kim, H. S., Koç, M., and Ni, J., "Determination of Appropriate Temperature Distribution for Warm Forming of Aluminum Alloys", Accepted for the NAMRC 32 Conference, The University of North Carolina at Charlotte, June 2004.

15. António, C.A.C., and Dourado N.M, Journal of Materials Processing Technology 121, 403-413 (2002).

16. Gao, L., Motsch, S., and Strano, M., Journal of Materials Processing Technology 129, 261-267 (2002).

17. Pilani, R., Narasimhan, K., Maiti, S. K., Singh, U. P., and Date, P. P., International Journal of Advanced Manufacturing Technology 16, 370-375 (2000). 